\title{
精氨酸对胰岛素释放和胰岛亚硝酸盐 产生的影响
}

秦茂春 王 智 朱文玉

(北京医科大学生理教研室, 北京 100083)

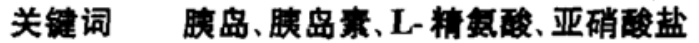

精氨酸可调节多种激素的释放. 近年来发现, L-精氨酸在哺乳动物体内可产生一氧化氮 (NO), 在神经系统、心血管系统及免疫系统中作为信息物质起重要作用 ${ }^{[1]}$. 关于 L- 精氨 酸 -NO 通路在胰岛素释放中的作用, 目前资料甚少. 本工作在分离培养的新生大鼠胰岛上, 观察 L-精氨酸对胰岛素释放和亚硝酸盐产生的影响, 初步探讨 L- 精氨酸 -NO 通路在胰岛素 分泌过程中的作用.

\section{1 材 料 和 方 法}

\section{1 新生大閶费㞧的分离和培养}

选用出生后 1 天的 Wistar 大鼠, 取出胰腺, 用无 $\mathrm{Ca}^{2+}$ Hank's 液洗净, 剪碎, 加人 V 型胶 原酶 (Sigma Co.) 消化 10-15min. 用冰冷的 Hank's 液终止消化, 静置后去上清, 沉积物即 为胰岛组织. 向胰岛中加人含 $10 \%$ 灭活小牛血清的 PMRI-1640 培养液, 移人培养瓶内, 在 $\mathrm{CO}_{2}$ 培养箱中培养 $18-20 \mathrm{~h}$, 将经过培养的胰岛换液洗涤, 接种在培养板上. 以 Hank's 液为 躬育液孵育 $1 \mathrm{~h}$, 取上清液测胰岛素. 以 PMRI-1640 为培养液, 培养 $24 \mathrm{~h}$, 取上清液测亚硝酸盐 含量.

\section{2 眱鴡素的测定}

从短期㸺育的培养板孔中取液 $50 \mu 1$, 用放射免疫法测定胰岛素浓度. 胰岛素放免药盒由 解放军海军放射免疫中心提供.

\section{3 亚硝酸盐的测定}

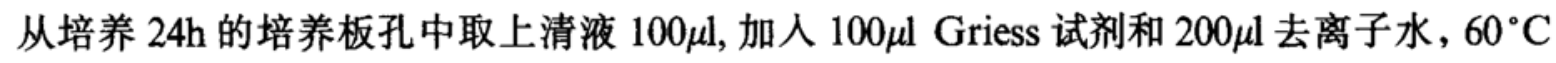
温育 $30 \mathrm{~min}$, 用紫外分光光度计 $\left(\lambda_{260-280}\right)$ 测亚硝酸盐含量.

实验数据以均数 \pm 标准误表示, 显著性用 $t$ 检验法检验.

\section{2 实 验结 果}

\section{1 不同浓度葡萄裙对胰岛素释放的影响}

在每个培养孔中加人大小中等均匀的胰岛 10 个, 孵育 $1 \mathrm{~h}$. 随着捊育液中葡萄糖浓度的

1993-07-01 收稿, 1994-01-26 收修改稿. 
增加, 胰岛素的释放量也明显增加 (图 1).

\section{2 不同浓度精氨酸对费屴素释放的影响}

在每孔中加 10 个胰岛睬育 $1 \mathrm{~h}$, 当摡育液中含有葡萄糖 $(55 \mathrm{mmol} / \mathrm{L})$ 时, $2.5,5.0 \mathrm{mmol} / \mathrm{L}$ 和 $10.0 \mathrm{mmol} / \mathrm{L}$ 的 L-精氨酸显著地刺激腌岛素释放, 分别比对照组增加 $31,92 \%$ 和 $190 \%$. 当捊育 液中不存在葡萄糖时, 精氨酸也能引起胰岛素释放增加, 但其刺激作用远小于有葡萄糖存在 时, $10 \mathrm{mmol} / \mathrm{L}$ 精氨酸引起的胰岛素释放量仅比对照组增加 $35 \%$, 表明葡萄糖对精氨酸的促腌 岛素释放有协同作用 (图 2).

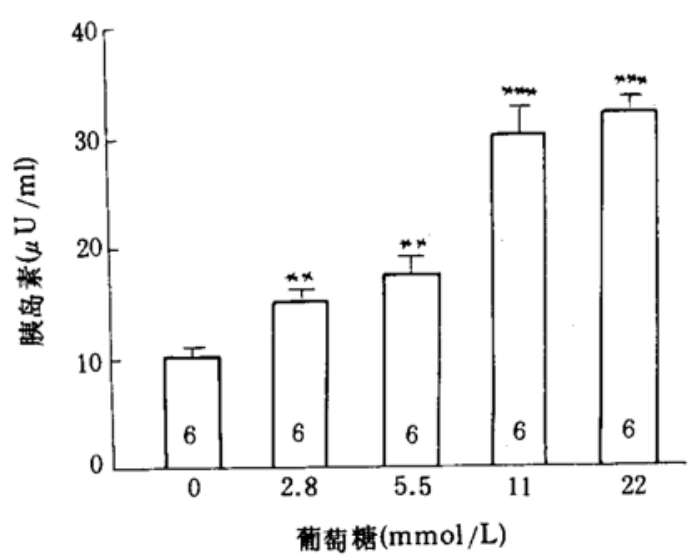

图 1 不同浓度葡萄糖对胰岛素释放的影响 与对照组相比, ${ }^{* *} p<0.05,{ }^{* * *} p<0.001$. 柱中数 字为实验例数

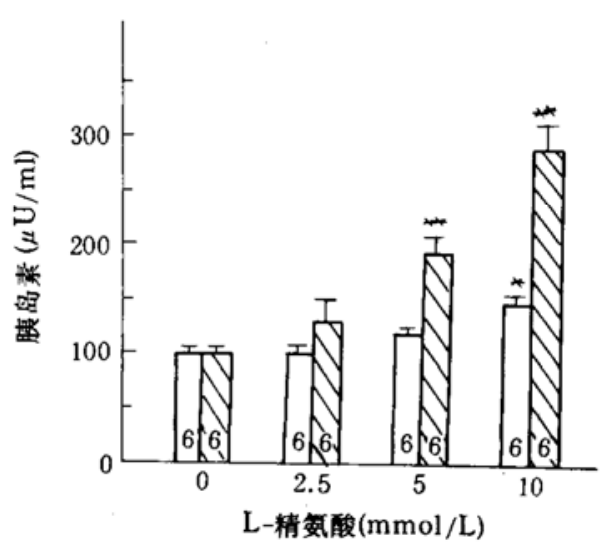

图 2 不同浓度 L-精氨酸对胰岛素释放的影响

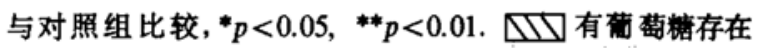
$(5.5 \mathrm{mmol} / \mathrm{L}), \square$ 无苚萄糖. 柱中数字为实验例数

\section{3 䐜岛数目对亚硝酸盐产生的影响}

将不同数目的胰岛在 PMRI-1640 培养过夜, 随着胰岛数目的增加, 亚硝酸盐的产量明显 增加 (图 3).

\section{4 不同浓度精量酸对胰岛亚硝酸盐产生的影响}

向每孔中加人 100 个胰岛, 培养 $24 \mathrm{~h}$, 由图 4 可见, 培养液中亚硝酸盐的产量随 L- 精氨酸

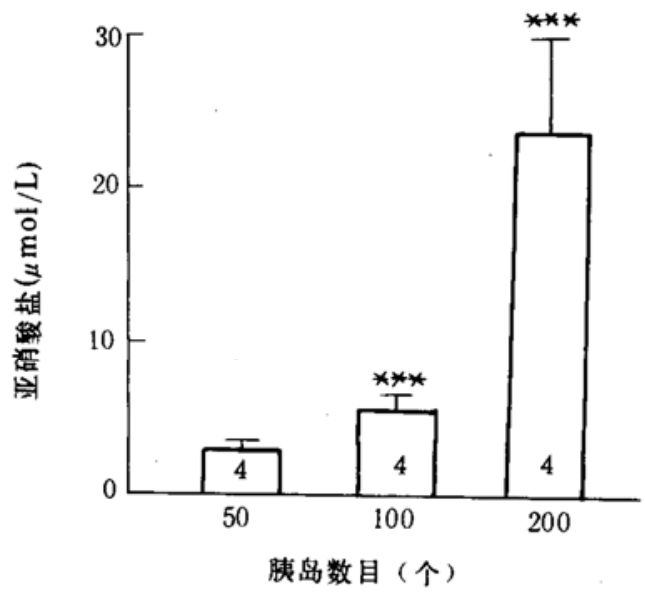

图 3 胰岛数目对亚硝酸盐产生的影响 与对照组比较, $* * * p<0.001$. 柱中数字为实验例数

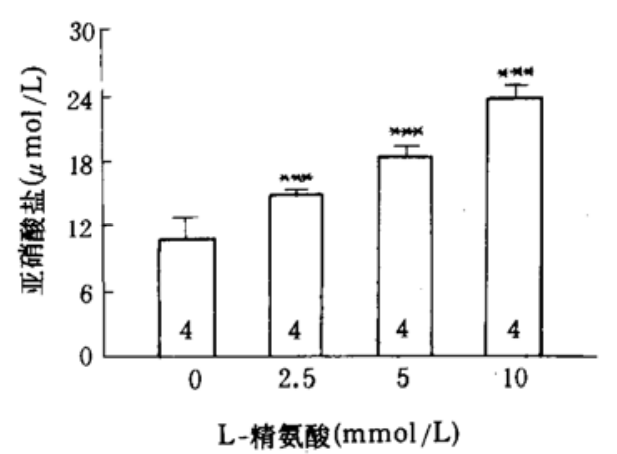

图 4 不同浓度精氨酸对胰岛亚硝酸盐产生的影响 与对照组比较, ${ }^{* * *} p<0.001$. 柱中数字为实验例数 
浓度的增加而有明显的上升.

\section{3 讨 论}

本实验选用新生大鼠胰岛,一方面是因为新生大鼠胰腺中胰岛的含量相对较多, 消化分离 时所需胶原酶少; 另一方面, 新生大鼠的胰岛与成年大鼠相比, 功能上常有较大差异 ${ }^{[2]}$, 精氨酸 对成年大鼠胰岛素释放的作用已有一些资料, 但对新生鼠胰岛的作用尚未见报道, 故从新生 大鼠角度分析 L- 精氨酸 -NO 通路在胰岛素分泌过程中的作用, 是对精氨酸研究的一个补 白.

较早的研究表明, 精氨酸的各种异构体及其衍生物, 均有促胰岛素释放的作用 ${ }^{[3]}$, 但对其作 用机制尚存有争议. 近年来发现的 L-精氨酸 -NO 通路, 为阐明其机制提供了新的思路. 在 哺乳动物体内的许多组织中, L-精氨酸在 NO 合成酶 (NOS) 的作用下合成 NO. NOS 有两种 类型: NOS I 和 NOS II. NOS I 在免疫刺激下表达, 产生大量 NO, 对细胞有杀伤作用; NOS II 在生理条件下即可表达, 产生小量或中等量的 NO, 它可激活鸟苷酸环化酶, 升高 cGMP 水 平, 产生一系列生理效应, 如扩张血管、抑制血小板聚集等 ${ }^{[4]}$. NO 在精氨酸促胰岛素释放中的 作用尚未阐明.

NO 性质极不稳定, 可迅速形成亚硝酸盐, 因此测定亚硝酸盐含量是反映 NO 产生的方法 之一. 本实验观察到 L- 精氨酸能增加新生大鼠分离的胰岛亚硝酸盐的产生和朠岛素的释 放, 且具有量效关系, 初步提示, L- 精氨酸 -NO 通路可能参与了 L- 精氨酸促胰岛素释放的过 程.

有报道指出, L-精氨酸和葡萄糖对胰岛内 $\mathrm{NO}$ 的产生有协同作用 ${ }^{[5]}$, 这与我们观察到的葡 萄糖加强精氨酸促胰岛素作用是一致的, 从而提示, 葡萄糖加强精氨酸促胰岛素的作用, 可能 是通过加强精氨酸引起的 NO 产生而实现的.

\section{参考 文 献}

[1] Collier, J., Vallance, P., Trends Pharmacol. Sci., 1989, 10:427-431.

[2] Ishizuka, J. et al., Pancreas, 1988, 3: 77-82.

[ 3] Malaisse, W. J., Mol. Cell Endocrinol., 1989, 67:81-91.

[ 4 ] Palmer, R. M. L., Ferrige, A. G., Moncada, S., Nature, 1987, 327:524- 526.

[ 5] Laychock, S. G., Modiea, M. E., Cavanaugh, C. T., Endocrinology, 1991, 129:3043-3052. 